\title{
Manual de los Reglamentos del Agua en Florida: Regulaciones de Descargas en Aguas Subterráneas a Nivel Federal ${ }^{1}$
}

Michael T. Olexa, Luke D'Isernia, Laura Minton, Dulcy Miller y Sara Corbett ${ }^{2}$

\section{Prefacio}

Este manual esta diseñado para proporcionar un resúmen autorizado, exacto y actual de las principales leyes Federales y de Florida que están directa o indirectamente relacionadas a la agricultura. Este manual debe proveer una vista general de los muchos derechos y responsabilidades que tienen los agricultores y propietarios de tierras agrícolas bajo las leyes tanto Federal como de Florida, así como también la información de los contactos apropiados para obtenerla con más detalle. Sin embargo, el lector debe estar advertido de que algunas partes de esta publicación podrían volverse obsoletas en cualquier momento, debido a que las leyes, reglas administrativas, y decisiones de la corte, sobre las cuales se basa este manual, se encuentran bajo revisión constante. Algunos detalles de las leyes citadas no se mencionan, debido a limitaciones de espacio.
Este manual es distribuido con la aclaración de que los autores no intentan proporcionar una asesoría legal o profesional, y que la información contenida aquí no debe ser considerada como un sustituto de asesoría profesional. En este manual, no se incluye toda la información para llevar a cabo el cumplimiento de las leyes Federales y de Florida y los reglamentos que rigen la protección del agua. Por estas razones, el uso de estos materiales por cualquier persona, constituyen un acuerdo para mantener libre de perjuicios a los autores, al Servicio de Extensión Cooperativa de Florida, al Instituto de los Alimentos y Ciencias Agrícolas y a la Universidad de Florida por reclamos de responsabilidad, daños o gastos provenientes de quien sea, por haberse referido o basado en la información contenida en este manual.

1. Este es el documento EDIS FE085, una publicación de Food and Resource Economics Department, Florida Cooperative Extension Service, Institute of Food and Agricultural Sciences, University of Florida, Gainesville, FL. Publicado Noviembre 2006. Por favor visite la página electrónica de EDIS en http://edis.ifas.ufl.edu.

2. Michael T. Olexa, profesor, Food and Resource Economics Department y director, Agricultural Law Center, University of Florida, Gainesville, FL, y presidente, Agricultural Law Committee, The Florida Bar; Luke D'Isernia, alumni, Levin CoIlege of Law, University of Florida, Gainesville, FL; Laura Minton, abogado, Dean, Mead, Egerton, Bloodworth, Capouano y Bozarth, PA, Orlando FL; Dulcy Miller, abogado, Foley and Lardner, LLP, Orlando, FL; y Sarah Corbett, abogado, Florida Second District Court of Appeal, Lakeland, FL. La traducción del ingles al español estuvo a cargo de Filiberto Reyes-Villanueva.

EI Instituto de Alimentos y Ciencias Agrícolas es un empleador que opera bajo Acción Afirmativa y provee Oportunidades Igualitarias, autorizado a proveer investigación, información educativa y otros servicios, únicamente a los individuos e instituciones que operan sin discriminación alguna con relación al credo, color, religión, edad, incapacidad, sexo, orientación sexual, estado civil, nacionalidad, opinion política o afiliaciones. Para más información sobre como obtener otras publicaciones de extensión, comuníquese con la oficina de Servicio de Extensión de su condado. Servicio de Extensión de la Florida / Instituto de Alimentos y Ciencias Agrícolas / Universidad de la Florida / Larry Arrington, Decano. 


\section{¿Cómo Regula el Gobierno Federal la Descarga de Agua Subterránea?}

La regulación federal de agua subterránea consiste de una variedad de directivas reglamentarias, administradas por una gran cantidad de agencias administrativas. Más de dieciséis partes de la legislación federal tienen algún efecto sobre las aguas subterráneas o tienen el potencial de afectar las actividades y programas relevantes para su uso.

\section{Ley del Agua Limpia}

La parte mas importante de la legislación federal es la Ley del Agua Limpia. El propósito principal de dicha Ley es la eliminación de las fuentes de contaminación de punto del agua superficial. El agua subterránea está implicada directamente debido al vínculo natural de la superficie y los recursos del agua subterránea. Cuando una parte contamina el agua superficial, es mas probable que se contamine el ciclo hidrológico, que cuando la contaminación es en el agua subterránea.

\section{Sistema Nacional de Eliminación de Descarga de Contaminantes}

El Sistema Nacional de Eliminación de Descargas de Contaminantes (SNEDC) sitúa las limitaciones de flujo sobre las fuentes de punto del agua contaminada (como un origen de contaminación reconocible tales como una pipa, pozo, o recipientes con filtración). Florida ha adoptado su propia versión de un programa de SNEDC. El DPA es la única agencia que emite los permisos del SNEDC con la excepción de los permisos de descarga de las aguas de lluvia, lo cual es la responsabilidad de los Distritos para el Manejo del Agua.

\section{Ley del Agua Potable Segura}

La Ley del Agua Potable Segura establece los estándares primarios y secundarios de la calidad del agua potable para los tipos de sistemas más grandes de agua pública que sirven al menos a 15 conexiones de servicio, o sirve a 25 o mas personas durante 60 días o mas fuera de temporada. La Ley del Agua Potable Segura también contiene disposiciones para la notificación al público cuando los niveles máximos de contaminantes de la calidad del agua están excedidos por los sistemas de agua individuales, y promueve mandatos para hacer cumplir la accion, cuando el agua potable no es tratada apropiadamente, o los estándares exceden la calidad del agua o impone cualquier riesgo indebido a la salud publica.

\section{Agradecimientos}

Los autores agradecen al personal de las agencias estatales y federales por su tiempo y asesoría en la preparación de este manual. Los autores agradecen especialmente a Richard Budell del Office of Agricultural Water Policy of the Florida Department of Agriculture and Consumer Services por el apoyo económico para el desarrollo de esta publicación. 